\title{
BMJ Open Factors associated with hypertension among adults in Nepal as per the Joint National Committee 7 and 2017 American College of Cardiology/ American Heart Association hypertension guidelines: a cross- sectional analysis of the demographic and health survey 2016
}

\author{
Rajat Das Gupta, ${ }^{\oplus 1,2}$ Sojib Bin Zaman, ${ }^{3}$ Kusum Wagle, ${ }^{4,5}$ Reese Crispen, ${ }^{6}$ \\ Mohammad Rashidul Hashan, ${ }^{7}$ Gulam Muhammed Al Kibria ${ }^{6}$
}

To cite: Das Gupta R, Bin Zaman S, Wagle $\mathrm{K}$, et al. Factors associated with hypertension among adults in Nepal as per the Joint National Committee 7 and 2017 American College of Cardiology/American Heart Association hypertension guidelines: a cross-sectional analysis of the demographic and health survey 2016. BMJ Open 2019:9:e030206. doi:10.1136/ bmjopen-2019-030206

- Prepublication history and additional material for this paper are available online. To view these files, please visit the journal online (http://dx.doi. org/10.1136/bmjopen-2019030206).

\section{Received 04 March 2019}

Revised 14 June 2019

Accepted 05 July 2019

Check for updates

(c) Author(s) (or their employer(s)) 2019. Re-use permitted under CC BY-NC. No commercial re-use. See rights and permissions. Published by BMJ.

For numbered affiliations see end of article.

Correspondence to Dr Rajat Das Gupta; rajat89.dasgupta@gmail.com

\section{ABSTRACT}

Objectives This study investigated the determinants of hypertension in Nepal according to both the Joint National Committee 7 (JNC7) and the American College of Cardiology/American Heart Association (2017 ACC/AHA) guidelines.

Design Cross-sectional study.

Setting This study used data collected from the 2016 Nepal Demographic and Health Survey data.

Participants 13393 weighted adults aged $\geq 18$ years enrolled by a stratified cluster sampling strategy were included in our analysis.

Primary and secondary outcome measures The primary outcome was hypertension, which was defined according to JNC7 (systolic blood pressure (SBP) $\geq 140 \mathrm{~mm}$ $\mathrm{Hg}$ and/or diastolic blood pressure (DBP) $\geq 90 \mathrm{~mm} \mathrm{Hg}$ ) and 2017 ACC/AHA guidelines (SBP $\geq 130 \mathrm{~mm} \mathrm{Hg}$ and/or DBP $\geq 80 \mathrm{~mm} \mathrm{Hg}$ ). Antihypertensive medication users were also classified as hypertensive. After descriptive analysis, multilevel logistic regression was applied to obtain ORs. Results About 21\% $(n=2827)$ and $44 \%(n=5918)$ of the individuals aged $\geq 18$ years were classified as hypertensive according to the JNC7 and 2017 ACC/AHA guidelines, respectively. Following factors were found to be significantly associated with hypertension according to the 2017 ACC/AHA guideline: $\geq 70$ years (adjusted OR (AOR) 5.2; 95\% Cl 4.3 to 6.2), 50-69 years (AOR 3.9; $95 \% \mathrm{Cl} 3.4$ to 4.4 ) and $30-49$ years (AOR $2.7 ; 95 \% \mathrm{Cl} 2.4$ to 3.0 ) age groups, male gender (AOR $1.7 ; 95 \% \mathrm{Cl} 1.6$ to 1.9), being overweight/obese (AOR 3.0; 95\% $\mathrm{Cl} 2.7$ to 3.3), residence in provinces 4 (AOR 1.5; $95 \% \mathrm{Cl} 1.2$ to 2.0 ) and 5 (AOR 1.5; 95\% Cl 1.2 to 1.9). No significant association was identified with household wealth status and ecological regions of residence using the 2017 ACC/AHA guideline. Conclusions Per both guidelines, multiple factors were associated with hypertension. Public health programme

\section{Strengths and limitations of this study}

- The study used a nationally representative sample covering both urban and rural areas including all provinces in Nepal, making the findings of the present study generalisable for Nepal.

- The survey used validated instrument to measure hypertension and validated tools for collecting the data, the probability of measurement error is less likely compared with other studies in Nepal.

- Blood pressure was measured on a single day, while longitudinal measurement is recommended by both the guidelines, creating a possibility of some misclassification bias.

- Except body mass index, the association of hypertension with other metabolic determinants, including diabetes mellitus or dyslipidaemia, family history and lifestyle factors (ie, smoking, physical activity, dietary habit and daily salt consumption), was not evaluated, as those data were not collected.

- The temporal relationship between the outcome variable and the explanatory variables could not be established due to the cross-sectional nature of the study.

aiming to prevent and control hypertension in Nepal should prioritise these factors and focus on individuals with a higher likelihood of hypertension irrespective of educational level, household wealth status and ecological regions of residence.

\section{INTRODUCTION}

In 2017, non-communicable diseases (NCDs) were attributable to around three-quarters 
of the total global mortalities and cardiovascular disease (CVD) was the dominant cause of NCD-related mortalities and morbidities. ${ }^{1}$ Uncontrolled hypertension is the leading risk factor of CVD. ${ }^{23}$ In the recent decades, the burden of hypertension is increasing in most low-income and middle-income countries, including countries in South Asia. ${ }^{45}$

Nepal is a South Asian country, which is currently facing epidemiological transitions with an increasing burden of NCDs, including hypertension. ${ }^{6}$ Different studies estimated the prevalence of hypertension in Nepal from $21 \%$ to $34 \% .^{7-12}$ Two wave of the STEP wise approach to Surveillance (STEPS) survey conducted by WHO estimated that the prevalence of hypertension increased from $21.5 \%$ in 2008 to $26.0 \%$ in 2013 among Nepalese aged 15-69 years. ${ }^{8} 12$ Nepal Demographic and Health Survey (NDHS 2016) is one of the latest surveys using a nationally representative sample to collect data on hypertension. ${ }^{13}$ Hasan et al. analysed the NDHS 2016 data and estimated that around $20 \%$ of the participants aged $\geq 18$ years were hypertensive. ${ }^{14}$ The prevalence of hypertension may change due to the introduction of a new guideline, which recategorises the cut-off point of blood pressure for defining hypertension. In 2017, the American College of Cardiology/American Heart Association (ACC/AHA) guideline for the prevention, detection, evaluation and management of high blood pressure in adults was released. ${ }^{15}$ This new guideline recategorises the cut-off value of systolic blood pressure (SBP) and diastolic blood pressure (DBP) in defining hypertension. ${ }^{15}$ Previously, the seventh report of the Joint National Committee 7 (JNC7) on prevention, detection, evaluation and treatment of high blood pressure or other practised guidelines defined hypertension as the SBP/DBP of $\geq 140 / 90 \mathrm{~mm} \mathrm{Hg} .{ }^{16}$ But the new guideline (2017 ACC/ AHA) considers a person as hypertensive if the SBP/DBP is $\geq 130 / 80 \mathrm{~mm} \mathrm{Hg}, 10 \mathrm{~mm} \mathrm{Hg}$ lower than the previous cut-off. ${ }^{15}$ This lower cut-off has reclassified a significant portion of the population as hypertensive who were previously classified as prehypertensive ${ }^{17-19}$ For instance, about $23 \%$ of the Nepalese adults could be reclassified as hypertensive following application of the new guideline, which could have both direct and indirect public health impacts in terms of preventative and curative services. ${ }^{17}$

In addition to estimating the prevalence, identifying the determinants is important to develop effective prevention and control strategies. Considering the change in the prevalence of hypertension, the determinants of hypertension could also differ due to a new cut-off. However, none of the earlier studies investigated determinants of hypertension according to the 2017 ACC/AHA guideline in Nepal. The updated knowledge on the determinants of hypertension according to the modified guideline will assist policy-makers and public health authorities in Nepal to identify those who should be prioritised with prevention and control programme. ${ }^{20} 21$

This study investigated and compared the determinants of hypertension among Nepalese adults using both the
JNC7 and 2017 ACC/AHA guidelines. Previous studies found that multiple factors, such as age, sex, body weight, socioeconomic status and regions of residence, are associated with hypertension in Nepal. ${ }^{1422}{ }^{23}$ Using the recent 2016 NDHS data, we evaluated the association of hypertension with these factors considering both the JNC7 and 2017 ACC/AHA guidelines.

\section{MATERIALS AND METHODS \\ Study design}

The NDHS 2016 was a cross-sectional survey. This survey was implemented by NEW ERA under the supervision of the ministry of health $(\mathrm{MoH})$, Nepal. The NDHS 2016 was conducted from June 2016 to January 2017. The survey used the revised frame of the 2011 National Population and Housing Census as the sampling frame. As a part of the reformation in 2015, Nepal was divided into seven provinces. ${ }^{13}$ The provinces were given name as province $1-7$. Provinces 2 and 5 are mainly located in the Terai region of Nepal (plain land) and rest of the provinces contain all three ecological regions: the Terai, hills and the mountains (snow-covered Himalayan region). Each of the provinces has different ethnic groups. ${ }^{24}$ Each province was further divided into urban and rural areas. The urban and rural areas were also divided into wards, which were considered as the primary sampling unit (PSU) for the survey. In the urban areas, the wards were divided into enumeration areas due to having more households than rural areas. ${ }^{13}$

\section{Sampling and data collection}

Stratified cluster sampling of households was used for data collection. In the rural area, a two-stage stratified sampling was used. In the first stage of sampling, PSUs $(n=199)$ were selected by probability proportional to their size, followed by systematic selection of households from an individual PSU. In the urban area, a three-stage stratified sampling was used. After selecting the PSUs $(n=184)$, EAs were randomly selected from PSUs in the second stage. Then, the households were selected by systematic selection in the third stage of sampling. In this way, a total of 11490 households (5520 households in urban areas and 5970 households in rural areas) were selected. ${ }^{13}$

NDHS used a standard, pretested and validated biomarker questionnaire (in the local context of Nepal) for to collect data on blood pressure measurements and anthropometry measurements (height and weight). All the men and women aged 15 years and above who were residents in half of the selected households were considered eligible for blood pressure measurements. The questionnaire was finalised in English and then translated and pretested in Nepali, Maithili and Bhojpuri language. ${ }^{13}$ The data collection took place from 19 June 2016 to 31 January 2017. Trained enumerators carried out the data collection. The data were collected by 16 teams. Each team comprised a supervisor, three female interviewers and one male interviewer. Two female members and 
the male member of the team were trained to measure the height and body weight. The male team member also received training on blood pressure measurement. Rigorous monitoring was done by ICF staff, quality control team and technical team from the $\mathrm{MoH}$ and the Nepal Health Research Council. ${ }^{13}$

\section{Outcome of interest}

Hypertension was considered as the outcome variable of this study. The target group of this study was adult Nepalese men and women aged 18 years and above. With an interval of 5 min between each measurement, for each individual, blood pressure was measured three times using an UA-767F/FAC (A\&D Medical) blood pressure monitor. The first measurement was discarded and the average of the second and third measurements was taken to identify the hypertensive status of the respondents. According to the JNC7 guideline, an individual having $\mathrm{SBP} \geq 140 \mathrm{~mm} \mathrm{Hg}$ and/or DBP $\geq 90 \mathrm{~mm} \mathrm{Hg}$ was considered hypertensive. ${ }^{16}$ According to the 2017 ACC/AHA guideline, having $\mathrm{SBP} \geq 130 \mathrm{~mm} \mathrm{Hg}$ and/or DBP $\geq 80 \mathrm{~mm}$ $\mathrm{Hg}$ was considered hypertension. ${ }^{15}$ Furthermore, the respondents were considered hypertensive irrespective of their blood pressure if they reported that they were taking antihypertensive medications.

\section{Explanatory variables}

Based on literature review and structure of the NDHS 2016 dataset, following possible explanatory variables were considered: age, sex, being overweight/obese, educational status, household wealth quintile and place, province and ecological regions of residence. The definitions and categories of study variables are summarised in Online supplementary table 1. Age, sex, educational status and household wealth components were reported by the participants. Place, province and ecological zone of residence were recorded based on the current residence location of the respondents. The body mass index (BMI) was calculated by dividing the respondent's weight (measured in kilogram) by height squared (in metre ${ }^{2}$ ). If the BMI of a participant was $\geq 25 \mathrm{~kg} / \mathrm{m}^{2}$, then the respondent was considered overweight/obese. ${ }^{25}$ The NDHS 2016 used principal component analysis of the selected assets (ie, household construction materials, types of water source and sanitation facilities, electricity and other belongings) to report the household wealth index, ${ }^{132627}$ which was further divided into quintiles.

\section{Statistical analysis}

First, univariate analyses of the selected variables were performed and were presented in number and percentages. Then, bivariate analyses (ie, cross-tabulation) were carried out between independent variables and the outcome of interest (ie, hypertension) according to both the JNC7 and 2017 ACC/AHA guidelines. The NDHS 2016 sample weight was used during descriptive analyses. After that, multilevel mixed-effects logistic regression analyses were performed to identify the determinants of hypertension according to both guidelines. During multilevel logistic regression, crude analysis was first performed between the outcome variable and each independent variable. Variables with a $\mathrm{p}<0.2$ were put into the final adjusted model. This predetermined $p$ value was considered sufficient to adjust additional residual effect. ${ }^{28}$ Both crude and adjusted ORs (COR and AOR, respectively) were reported along with 95\% CIs. Multicollinearity among the covariates was assessed using variance inflation factor and no significant multicollinearity was found. Stata V.13.0 was used for data analysis. ${ }^{29}$ The authors followed the guidelines outlined in the 'Strengthening the Reporting of Observational Studies in Epidemiology' statement in writing the manuscript (online supplementary table 2).

Before data collection, written informed consent was taken from the head of the households of the respondents.

\section{Patient and public involvement}

Patients and the public were not involved in the design or planning of the study.

\section{FINDINGS}

\section{Background characteristics of the respondents}

The overall background characteristics of the respondents, as well as the background characteristics according to the hypertension status, are presented in table 1. A total of 13393 individuals participated in this study of which $69.8 \%$ were less than 50 years of age, $58.0 \%$ were females and $21.5 \%$ were overweight/obese. A substantial proportion $(41.6 \%)$ of participants had no formal education. More than $60 \%$ of the respondents were from the urban areas. About half of the participants were residents of the Terai region $(49.6 \%)$, followed by people from the Hills (44.0\%).

\section{Prevalence and factors associated with hypertension according to guidelines}

Among 13393 participants, around 21.0\% ( $\mathrm{n}=2827)$ and $44.0 \%(\mathrm{n}=5918)$ of the respondents were classified as hypertensive according to the JNC7 and 2017 ACC/AHA guidelines, respectively. Both guidelines showed that the prevalence of hypertension significantly increased with age $(p<0.001)$ and males were more likely to be hypertensive than females (male vs female: JNC7: $25.4 \%$ vs $18.0 \%, \mathrm{p}<0.001$; ACC/AHA: $50.9 \%$ vs $39.3 \%, \mathrm{p}<0.001$ ). The prevalence of hypertension was higher among the overweight/obese individuals compared with those who had normal weight (overweight/obese vs normal weight: JNC7: $35.6 \%$ vs $17.1 \%$, p $<0.001$; ACC/AHA: $64.1 \%$ vs $38.7 \%, \mathrm{p}<0.001)$. According to both guidelines, the prevalence of hypertension was higher among respondents from the richest quintiles $(p<0.001)$, among residents of province $4(p<0.001)$, and from the Hills $(p<0.001)$ compared with participants belonging to other wealth groups, other provinces and other ecological region, respectively (table 1 ). 
Table 1 Distribution of the respondents according to hypertension status under guidelines, $n(\%)(n=13393)$

\begin{tabular}{|c|c|c|c|c|c|c|c|}
\hline \multirow[b]{3}{*}{ Characteristics } & \multirow{3}{*}{$\begin{array}{l}\text { Overall, } \\
N=13393 \\
n(\%) \dagger\end{array}$} & \multicolumn{6}{|c|}{ Respondents with hypertension under guidelines } \\
\hline & & \multicolumn{3}{|l|}{ JNC7 } & \multicolumn{3}{|c|}{2017 ACC/AHA } \\
\hline & & $\begin{array}{l}\text { Yes }(n=2827) \\
n(\%)^{*}\end{array}$ & $\begin{array}{l}\text { No }(n=10566) \\
n(\%)^{*}\end{array}$ & $P$ value & $\begin{array}{l}\text { Yes }(n=5918) \\
n(\%)^{*}\end{array}$ & $\begin{array}{l}\text { No }(n=7474) \\
n(\%)^{*}\end{array}$ & $P$ value \\
\hline \multicolumn{8}{|l|}{ Age (years) } \\
\hline $18-29$ & $4337(32.4)$ & $266(6.1)$ & 4071 (93.9) & $<0.001 \ddagger$ & 1079 (24.9) & $3257(75.1)$ & $<0.001 f$ \\
\hline$\geq 70$ & $866(6.4)$ & $377(43.5)$ & $489(56.5)$ & & $525(60.6)$ & $341(39.4)$ & \\
\hline \multicolumn{8}{|l|}{ Sex } \\
\hline Male & $5620(42.0)$ & $1429(25.4)$ & $4191(39.7)$ & $<0.001 \ddagger$ & $2863(50.9)$ & $2757(49.1)$ & $<0.001 \ddagger$ \\
\hline Female & $7773(58.0)$ & $1398(18.0)$ & $6375(82.0)$ & & 3055 (39.3) & $4717(60.7)$ & \\
\hline \multicolumn{8}{|l|}{ Obese/overweight } \\
\hline \multicolumn{8}{|l|}{ Education } \\
\hline No formal education & $5572(41.6)$ & $1365(24.5)$ & 4208 (75.5) & $<0.001 \ddagger$ & $2649(47.5)$ & $2922(52.5)$ & $<0.001 \ddagger$ \\
\hline Primary & $2172(16.2)$ & $473(21.8)$ & 1698 (78.2) & & $975(44.9)$ & $1197(55.1)$ & \\
\hline Secondary & $3699(27.6)$ & $680(18.4)$ & $3019(81.6)$ & & 1549 (41.9) & $2150(58.1)$ & \\
\hline Tertiary & $1950(14.6)$ & $309(15.8)$ & $1641(84.2)$ & & 745 (38.2) & $1205(61.8)$ & \\
\hline \multicolumn{8}{|l|}{ Household wealth index } \\
\hline Poorest & $2396(17.9)$ & $449(18.7)$ & 1947 (81.3) & $<0.001 \ddagger$ & $1043(43.5)$ & $1353(56.5)$ & $<0.001 \neq$ \\
\hline Poorer & $2594(19.5)$ & $548(21.1)$ & 2046 (80.9) & & $1163(44.8)$ & $1432(55.2)$ & \\
\hline Middle & 2666 (19.9) & $475(17.8)$ & 2191 (82.2) & & 1075 (40.3) & $1590(59.7)$ & \\
\hline \multicolumn{8}{|l|}{ Provinces } \\
\hline Province 1 & $2365(17.7)$ & $475(20.1)$ & $1889(79.9)$ & $<0.001 \ddagger$ & $1002(42.4)$ & $1362(57.6)$ & $<0.001 \ddagger$ \\
\hline Province 2 & $2748(20.5)$ & $440(16.0)$ & $2308(84.0)$ & & 966 (35.2) & $1782(64.8)$ & \\
\hline Province 3 & $2933(21.9)$ & $732(25.0)$ & $2202(75.0)$ & & 1434 (48.9) & $1499(51.2)$ & \\
\hline Province 4 & $1380(10.3)$ & $398(28.8)$ & $982(71.2)$ & & $765(55.4)$ & $616(44.6)$ & \\
\hline Province 5 & 2184 (16.3) & 509 (23.3) & $1675(76.7)$ & & $1084(49.6)$ & $1100(50.4)$ & \\
\hline Province 6 & $674(5.0)$ & 109 (16.2) & $565(83.8)$ & & 264 (39.2) & $410(60.8)$ & \\
\hline Province 7 & 1109 (8.3) & $164(14.8)$ & 945 (85.2) & & $404(36.4)$ & 705 (65.6) & \\
\hline \multicolumn{8}{|l|}{ Ecological region } \\
\hline Mountain & $856(6.4)$ & 155 (18.1) & 701 (81.9) & $<0.001 \ddagger$ & 351 (41.0) & 505 (59.0) & $<0.001 \ddagger$ \\
\hline Hills & 5895 (44.0) & $1426(24.2)$ & $4470(75.8)$ & & 2877 (48.8) & 3018 (51.2) & \\
\hline The Terai & 6642 (49.6) & 1246 (18.8) & $5395(81.2)$ & & $2690(40.5)$ & 3951 (59.5) & \\
\hline
\end{tabular}

${ }^{*}$ Row percentage.

†Column percentage.

$\ddagger \mathrm{P}<0.05$.

ACC/AHA, American College of Cardiology/American Heart Association; JNC7, Joint National Committee 7.

The CORs and AORs of the factors associated with hypertension according to both guidelines are presented in table 2. According to the JNC7 guideline, the odds of hypertension increased with age with the highest AOR for the age group $\geq 70$ years (AOR 14.6;
95\% CI 11.7 to 18.2 ), followed by $50-69$ years (AOR 8.0; 95\% CI 6.8 to 9.6 ) and 30-49 years (AOR 3.6; 95\% CI 3.1 to 4.2 ) age groups. Males had $50 \%$ increased odds of hypertension in comparison to their female counterparts (AOR 1.5; 95\% CI: 1.4 to 1.7). Overweight/ 
Table 2 Results of logistic regression analyses to compare crude and adjusted ORs (COR and AOR) for the factors associated with hypertension according to guidelines

\begin{tabular}{|c|c|c|c|c|c|c|c|c|}
\hline Traits & \multicolumn{4}{|c|}{ COR $(95 \% \mathrm{Cl})$} & \multicolumn{4}{|c|}{ AOR (95\% CI) } \\
\hline \multicolumn{9}{|l|}{ Age (in years) } \\
\hline $30-49$ & $4.4^{\star \star \star}$ & (3.8 to 5.1 ) & $3.2^{\star \star \star}$ & (2.9 to 3.5 ) & $3.6^{\star \star \star}$ & (3.1 to 4.2 ) & $2.7^{\star \star \star}$ & (2.4 to 3.0 ) \\
\hline $50-69$ & $8.9^{\star \star \star}$ & (7.6 to 10.3 ) & $4.4^{\star \star \star}$ & (3.9 to 4.9 ) & $8.0^{\star \star \star}$ & (6.8 to 9.6$)$ & $3.9^{\star \star \star}$ & (3.4 to 4.4 ) \\
\hline \multicolumn{9}{|l|}{ Sex } \\
\hline Male & $1.6^{\star \star \star}$ & (1.5 to 1.8$)$ & $1.7^{* \star *}$ & (1.6 to 1.8$)$ & $1.5^{\star \star \star}$ & (1.4 to 1.7$)$ & $1.7^{\star \star \star}$ & (1.6 to 1.9$)$ \\
\hline Female & Ref. & & Ref. & & Ref. & & Ref. & \\
\hline \multicolumn{9}{|l|}{ Overweight/obesity } \\
\hline & Ref. & & Ref. & & Ref. & & Ref. & \\
\hline Primary & $0.8^{\star \star \star}$ & (0.7 to 0.9$)$ & $0.9^{\star \star}$ & (0.8 to 0.9$)$ & 1.1 & (0.9 to 1.2$)$ & 1.0 & (0.9 to 1.1$)$ \\
\hline Secondary & $0.5^{\star \star \star}$ & (0.5 to 0.6$)$ & $0.7^{\star \star \star}$ & (0.6 to 0.7$)$ & 1.0 & (0.9 to 1.2$)$ & 1.0 & (0.9 to 1.1$)$ \\
\hline College or higher & $0.4^{\star \star \star}$ & (0.4 to 0.5$)$ & $0.5^{\star \star \star}$ & (0.5 to 0.6$)$ & 1.0 & (0.8 to 1.2$)$ & 0.9 & (0.8 to 1.1$)$ \\
\hline \multicolumn{9}{|c|}{ Household wealth status } \\
\hline Poorest & Ref. & & Ref. & & Ref. & & Ref. & \\
\hline Poorer & $1.1^{*}$ & (1.0 to 1.3$)$ & 1.0 & (0.9 to 1.2$)$ & 1.2 & (1.0 to 1.4$)$ & 1.0 & (0.9 to 1.2 ) \\
\hline Middle & 1.0 & (0.9 to 1.2$)$ & 1.0 & (0.9 to 1.2 ) & 1.1 & (0.9 to 1.3 ) & 1.1 & (0.9 to 1.3 ) \\
\hline Richer & $1.1^{*}$ & (1.0 to 1.3 ) & 1.0 & (0.9 to 1.2$)$ & 1.1 & (0.9 to 1.4$)$ & 1.0 & (0.9 to 1.2 ) \\
\hline Richest & 1.7 & (1.4 to 2.0 ) & $1.4^{\star \star \star}$ & (1.2 to 0.16$)$ & $1.4^{\star \star}$ & (1.1 to 1.7$)$ & 1.1 & (0.9 to 1.3 ) \\
\hline \multicolumn{9}{|l|}{ Provinces } \\
\hline Province 3 & $1.3^{*}$ & (1.0 to 1.7$)$ & $1.4^{\star \star}$ & (1.2 to 1.8$)$ & 1.1 & (0.8 to 1.4 ) & 1.3 & (1.0 to 1.7 ) \\
\hline Province 4 & $1.6^{\star \star \star *}$ & (1.3 to 2.0 ) & $1.7^{\star \star \star}$ & (1.4 to 2.2 ) & $1.4^{*}$ & (1.1 to 1.8$)$ & $1.5^{\star \star}$ & (1.2 to 2.0 ) \\
\hline Province 5 & $1.2^{*}$ & (0.9 to 1.5$)$ & $1.3^{*}$ & (1.1 to 1.7$)$ & $1.3^{*}$ & (1.0 to 1.7$)$ & $1.5^{\star \star}$ & (1.2 to 1.9 ) \\
\hline Province 6 & $0.8^{*}$ & (0.6 to 1.0$)$ & 0.9 & (0.7 to 1.1$)$ & 1.0 & (0.7 to 1.3 ) & 1.0 & (0.8 to 1.4$)$ \\
\hline Province 7 & $0.7^{* *}$ & (0.5 to 0.9$)$ & 0.8 & (0.6 to 1.0$)$ & 0.8 & (0.6 to 1.1$)$ & 0.9 & (0.7 to 1.2$)$ \\
\hline \multicolumn{9}{|l|}{ Ecological region } \\
\hline Mountains & Ref. & & Ref. & & Ref. & & Ref. & \\
\hline Hills & $1.6^{\star \star}$ & (1.2 to 2.1 ) & 1.2 & (0.9 to 1.7$)$ & $1.6^{\star \star \star}$ & $(1.2-2.1)$ & 1.2 & (0.9 to 1.7$)$ \\
\hline The Terai & $1.2^{*}$ & (0.9 to 1.6$)$ & 1.0 & (0.7 to 1.4$)$ & 1.1 & $(0.9-1.5)$ & 1.0 & (0.7 to 1.4$)$ \\
\hline \multicolumn{9}{|l|}{ Model fitness } \\
\hline AIC & & & 11592 & & & & $1607 c$ & \\
\hline
\end{tabular}

Variables with $\mathrm{p}<0.2$ from unadjusted model were included into multivariable analysis.

${ }^{*} \mathrm{P}<0.05,{ }^{*} \mathrm{P}<0.01,{ }^{* *} \mathrm{P}<0.001$.

ACC/AHA, American College of Cardiology/ American Heart Association; ANC, antenatal care; JNC7, Joint National Committee 7.

obesity (AOR 2.7, 95\% CI 2.4 to 3.0) also had positive association. The odds of being classified as hypertensive increased with a higher wealth index; only the richest quintile had (AOR 1.4; 95\% CI 1.2 to 1.7 ) significant association. Compared with province 1, respondents living in province 4 (AOR 1.4;95\% CI 1.1 to 1.8 ) and province 5 (AOR 1.3; 95\% CI 1.0 to 1.7 ) were more likely to be hypertensive. Education level, rural-urban 
place of residence and ecological zone of residence had no significant association.

Although the magnitude was not the same, similar factors were associated with hypertension according to the 2017 ACC/AHA guideline, except the educational status, household wealth status and the ecological regions (table 2). Hypertension was significantly associated with all three age groups: $\geq 70$ years (AOR 5.2; $95 \%$ CI 4.3 to 6.2), 50-69 years (AOR 3.9; 95\% CI 3.4 to 4.4) and 30-49 years (AOR 2.7; 95\% CI 2.4 to 3.0). Among other factors, male (AOR 1.7; 95\% CI 1.6 to 1.9), being overweight/ obese (AOR 3.0; 95\% CI 2.7 to 3.3), residing in Province 4 (AOR 1.5; $95 \%$ CI 1.2 to 2.0) and province 5 (AOR 1.5; $95 \%$ CI 1.2 to 1.9 ) had significant association.

\section{DISCUSSION}

This study identified the factors associated with hypertension among Nepalese adults using both the JNC7 and 2017 ACC/AHA guidelines and then compared that across both guidelines. Age, sex, overweight/obesity and province of residence were significantly associated with hypertension according to both guidelines. On the other hand, household wealth status and ecological zone of residence were only significant per the JNC7 guideline. Factors associated with hypertension according to the JNC7 guideline's cut-off in this study were also observed by previous studies that analysed the NDHS 2016 data. ${ }^{1422} 23$

The odds of hypertension increased with advancing age. Around $60 \%$ of the individuals aged $\geq 70$ years were hypertensive according to the 2017 ACC/AHA guideline. It is known that age is a non-modifiable risk factors of hypertension. ${ }^{30}$ Previous studies found that the likelihood of having hypertension increases with age due to structural changes in the cardiovascular systems along with other comorbidities. ${ }^{31}$ As previously stated, Nepal is currently undergoing demographic transition and the number of aged population is likely to increase in the coming days. ${ }^{32}$ As a result, the burden of hypertension is more likely to increase. ${ }^{33}$ Public health programme should focus on educating the elderly population about hypertension control.

Males had higher likelihood of hypertension than females. Similar findings were identified in other settings. ${ }^{34-36}$ Sex is a non-modifiable risk factor of hypertension. ${ }^{37}$ It is hypothesised that endogenous oestradiol in premenopausal females has a protective role against hypertension. Animal models suggest that sex differences in T-cells and activation of the renin-angiotensin system may also contribute to higher blood pressure level among males. ${ }^{38} 39$ For prevention and control purposes, public health programme in Nepal should aim to increase awareness among males.

Overweight/obese individuals were three times more likely to be hypertensive than those with a normal BMI in this study. Excessive weight predisposes a person to hypertension, which could increase the risk of CVD. ${ }^{40}$ Overweight/obesity causes raised blood pressure by increasing sympathetic nervous system activity and increased renal sodium retention due to impaired pressure natriuresis. ${ }^{41}$ Obesity is also associated with impaired endothelial function which in turn increases the blood pressure. ${ }^{42}$ Also overweight/obesity is associated with type 2 diabetes mellitus and chronic kidney diseases, which in turn predispose a person to hypertension. ${ }^{43}$ As Nepal is currently going through nutritional transition and the burden of overweight and obesity is increasing in both urban and rural areas, the burden of hypertension is more likely to increase in the upcoming days unless this problem is addressed with a multifaceted approach. ${ }^{44}$ Residents in provinces 4 and 5 had higher likelihood of hypertension. These provinces had the highest prevalence of hypertension according to the 2017 ACC/AHA guideline. ${ }^{17}$ Further studies are warranted to understand the factors, which influence the high prevalence of hypertension in these provinces. It is also important to focusing regions which had higher prevalence or odds of hypertension in order to reduce the disease burden.

Although similar to previous studies, hypertension cut-off as per the JNC7 guideline had positive association with household wealth status, ${ }^{22}$ it was not associated per the 2017 ACC/AHA guideline's cut-off. This may be due to the modification of the SBP/DBP threshold; therefore, a large proportion of individuals belonging to lower wealth quintiles were reclassified as hypertensive. ${ }^{17}$ The same explanation could be put forward to understand the association of ecological zones of residence. ${ }^{17}$

The relationships of age, sex, being overweight/obese and province of residence with hypertension according to the both guidelines could be due to the fact that the same factors were associated with prehypertension according to the JNC7 guideline. ${ }^{22}$ To prevent complications of hypertension, including reducing the burdens of NCDs in Nepal, prevention and control programme should prioritise these known determinants irrespective of socioeconomic status or place of residence.

To the best of our knowledge, this is the first study that investigated the determinants of hypertension according to the 2017 ACC/AHA guideline and then compared it with the determinants identified according to the JNC7 guideline in the context of Nepal. This study has several strengths. The NDHS 2016 used a nationally representative sample covering both urban and rural area including all provinces in Nepal; these made the findings of the present study generalisable for Nepal. The NDHS 2016 had over a $95 \%$ response rate for blood pressure measurement. ${ }^{13}$ Moreover, as the NDHS 2016 used validated instrument to measure hypertension and validated tools for collecting data, the probability of measurement error is less in this study, compared with other studies in Nepal. ${ }^{13}$

The limitations of the study also warrant discussion. The NDHS 2016 measured the blood pressure on a single day, while longitudinal measurement is recommended by both guidelines. ${ }^{910}$ As a result, there may be chances of some misclassification bias. Except BMI, the association 
of hypertension with other metabolic determinants, including diabetes mellitus or dyslipidaemia, family history and lifestyle factors (eg, smoking, physical activity, dietary habit, or daily salt consumption), was not evaluated as those data were not collected. Finally, as the NDHS 2016 was a cross-sectional survey, the temporal relationships between the outcome variable and the explanatory variables could not be established. ${ }^{13}$

\section{CONCLUSIONS}

Although the number of determinants per the 2017 ACC/AHA guideline was lower than the number of determinants per the JNC7 guideline, this study reidentified several known determinants of hypertension using the new guideline's cut-off points. Associated factors from different levels indicate that a comprehensive approach is required to address the factors associated with hypertension. To reduce the burden of hypertension and its future complications, it is important to prioritise the factors that were positively associated with hypertension; public health programme in Nepal should aim to increase awareness among people who are overweight/ obese, members of the older age group, male or residents of provinces 4 and 5 .

\section{Author affiliations}

${ }^{1}$ Centre for Non-Communicable Diseases and Nutrition, BRAC James P Grant School of Public Health, BRAC University, Dhaka, Bangladesh

${ }^{2}$ Centre for Science of Implementation and Scale-Up, BRAC James P Grant School of Public Health, BRAC University, Dhaka, Bangladesh

${ }^{3}$ Maternal and Child Health Division, International Centre for Diarrhoeal Disease Research, Bangladesh (icddr,b), Dhaka, Bangladesh

${ }^{4}$ Research Division, Center for Research on Environment Health and Population Activities, Kathmandu, Nepal

${ }^{5}$ Department of Public Health, Om Health Campus Pvt. Ltd, Kathmandu, Nepal ${ }^{6}$ Department of Epidemiology and Public Health, University of Maryland, Baltimore, Maryland, USA

${ }^{7}$ Department of Medicine, Dhaka Medical College and Hospital, Dhaka, Bangladesh

Contributors RDG and GMAK conceptualised the study. RDG, SBZ, KW and GMAK designed the study and acquired the data. RDG, SBZ, RC and GMAK conducted the data analysis. RDG, SBZ, KW, RC, MRH and GMAK interpreted the data. RDG and GMAK prepared the first draft. RDG, SBZ, KW, RC, MRH and GMAK participated in critical revision of the manuscript and contributed to its intellectual improvement. All authors went through the final draft and approved it for submission.

Funding The authors have not declared a specific grant for this research from any funding agency in the public, commercial or not-for-profit sectors.

Competing interests None declared.

Ethics approval The Nepal Health Research Council and ICF International, Rockville, Maryland, USA approved the NDHS 2016 protocol. The electronic approval to use the dataset for this study was obtained from ICF International in February 2019.

Provenance and peer review Not commissioned; externally peer reviewed.

Data availability statement Data are available in a public, open access repository.

Open access This is an open access article distributed in accordance with the Creative Commons Attribution Non Commercial (CC BY-NC 4.0) license, which permits others to distribute, remix, adapt, build upon this work non-commercially, and license their derivative works on different terms, provided the original work is properly cited, appropriate credit is given, any changes made indicated, and the use is non-commercial. See: http://creativecommons.org/licenses/by-nc/4.0/.

\section{REFERENCES}

1. GBD 2017 Causes of Death Collaborators. Global, regional, and national age-sex-specific mortality for 282 causes of death in 195 countries and territories, 1980-2017: a systematic analysis for the global burden of disease study 2017. Lancet 2018;392:1736-88.

2. Zhou D, Xi B, Zhao M, et al. Uncontrolled hypertension increases risk of all-cause and cardiovascular disease mortality in US adults: the NHANES III linked mortality study. Sci Rep 2018;8)::9418. 20;.10.1038/s41598-018-27377-2

3. Schmieder RE. End organ damage in hypertension. Dtsch Arztebl Int 2010;107:866-73.

4. Sarki AM, Nduka CU, Stranges S, et al. Prevalence of hypertension in low- and middle-income countries: a systematic review and metaanalysis. Medicine 2015;94:e1959.

5. Danaei G, Finucane MM, Lin JK, et al. National, regional, and global trends in systolic blood pressure since 1980: systematic analysis of health examination surveys and epidemiological studies with 786 country-years and $5 \cdot 4$ million participants. The Lancet 2011;377:568-77.

6. Mishra SR, Neupane D, Bhandari PM, et al. Burgeoning burden of non-communicable diseases in Nepal: a scoping review. Global Health 2015;11:32.

7. Shrestha UK, Singh DL, Bhattarai MD. The prevalence of hypertension and diabetes defined by fasting and 2-h plasma glucose criteria in urban Nepal. Diabet Med 2006;23:1130-5.

8. Karki KB, Dahal BR, Regmi A, Kathmandu: Ministry of Health and Population Government of Nepal,Society for Local Integrated Development Nepal (SOLID Nepal) and WHO. Who steps surveillance: non communicable diseases risk factors survey 2008 2008.

9. Vaidya A, Pathak RP, Pandey MR. Prevalence of hypertension in Nepalese community triples in 25 years: a repeat cross-sectional study in rural Kathmandu. Indian Heart J 2012;64:128-31.

10. Mehta K, Karki P, Lamsal M, et al. Hyperglycemia, glucose intolerance, hypertension and socioeconomic position in eastern Nepal. Southeast Asian J Trop Med Public Health 2011;42.

11. Sharma SK, Ghimire A, Radhakrishnan J, et al. Prevalence of hypertension, obesity, diabetes, and metabolic syndrome in Nepal. Int J Hypertens 2011;2011:821971.

12. Aryal KK, Mehata S, Neupane S, et al. The burden and determinants of non communicable diseases risk factors in Nepal: findings from a nationwide steps survey. PLoS One 2015;10:e0134834.

13. Ministry of Health and Population (MoHP). Nepal New ERA and ICF International Inc. In: Nepal demographic and health survey 2016. Kathmandu: Ministry of Health and Population, 2017.

14. Hasan M, Sutradhar I, Akter T, et al. Prevalence and determinants of hypertension among adult population in Nepal: data from Nepal demographic and health survey 2016. PLoS One 2018;13:e0198028.

15. Whelton PK, Carey RM, Aronow WS, ACC/AHA/AAPA/ABC/ACPM/ AGS/APhA/ASH/ASPC/NMA/PCNA Guideline for the Prevention, Detection, Evaluation. Management of high blood pressure in adults: a report of the American College of Cardiology/American heart association Task force on clinical practice guidelines. Hypertension 2018;71:1269-324.

16. Chobanian AV, Bakris GL, Black HR, et al. The seventh report of the joint National Committee on prevention, detection, evaluation, and treatment of high blood pressure: the JNC 7 report. JAMA 2003;289:2560-72.

17. Kibria GMA, Swasey K, KC A, et al. Estimated change in prevalence of hypertension in Nepal following application of the 2017 ACC/AHA guideline. JAMA Network Open 2018;1:e180606-e.

18. Kibria GMA, Swasey K, Choudhury A, et al. The new 2017 ACC/AHA guideline for classification of hypertension: changes in prevalence of hypertension among adults in Bangladesh. J Hum Hypertens 2018;32:608-16.

19. Hernández-Vásquez A, New SM. ACC/AHA hypertension guideline: implications for a Latin American country like Peru. Eur J Prev Cardiol 2017;2018.

20. Antay-Bedregal D, Camargo-Revello E, Alvarado GF. Associated factors vs risk factors in cross-sectional studies. Patient Prefer Adherence 2015;9:1635-6.

21. Barroga EF, Kojima T. Research study designs: an appraisal for peer reviewers and science editors. In: Sci E, ed. 39, 2013: 44-5.

22. Kibria GMA, Swasey K, Sharmeen A, et al. Prevalence and associated factors of pre-hypertension and hypertension in Nepal: analysis of the Nepal demographic and health survey 2016. Health Sci Rep 2018;1:e83.10.1002/hsr2.83

23. Mehata S, Shrestha N, Mehta R, et al. Prevalence, awareness, treatment and control of hypertension in Nepal: data from nationally representative population-based cross-sectional study. J Hypertens 2018;36:1680-8. 
24. Nepali S, Ghale S, Hachhethu K, et al. Federal Nepal: Socio-Cultural Profiles of the Seven Provinces. Kathmandu: Governance Facility, 2018.

25. Executive summary of the clinical guidelines on the identification, evaluation, and treatment of overweight and obesity in adults. Arch Intern Med 1998;158:1855-67.

26. Filmer D, Pritchett LH. Estimating wealth effects without expenditure data-or tears: an application to educational enrollments in states of India. Demography 2001;38:115-32.

27. Jolliffe IT, Cadima J. Principal component analysis: a review and recent developments. philosophical transactions series a. Philos Trans A Math Phys Eng Sci 2065;2016.

28. Maldonado G, Greenland S. Simulation study of ConfounderSelection strategies. Am J Epidemiol 1993;138:923-36.

29. Stata Corp L. Stata 13. College Station: Stata Corp LP, 2014.

30. Lee S-H, Kim Y-S, Sunwoo S, et al. A retrospective cohort study on obesity and hypertension risk among Korean adults. J Korean Med Sci 2005;20:188-95.

31. Fleg JL, Strait J. Age-Associated changes in cardiovascular structure and function: a fertile milieu for future disease. Heart Fail Rev 2012;17:545-54.

32. Feeney G, Thapa S, Sharma KR. One and a half centuries of demographic transition in Nepal. J Health Popul Nutr 2001;19:160-6.

33. Engelgau MM, El-Saharty S, Kudesia P, et al. Capitalizing on the demographic transition: tackling noncommunicable diseases in. South Asia: The World Bank, 2011.
34. Chow CKet al. Prevalence, awareness, treatment, and control of hypertension in rural and urban communities in high-, middle-, and low-income countries. JAMA 2013;310:959-68.

35. Ghosh S, Mukhopadhyay S, Barik A. Sex differences in the risk profile of hypertension: a cross-sectional study. BMJ Open 2016;6:e010085.

36. van de Vijver SJM, Oti SO, Agyemang C, et al. Prevalence, awareness, treatment and control of hypertension among slum dwellers in Nairobi, Kenya. J Hypertens 2013;31:1018-24.

37. Sandberg K, Ji H. Sex differences in primary hypertension. Biol Sex Differ 2012;3:7.

38. Ashraf MS, Vongpatanasin W. Estrogen and hypertension. Curr Hypertens Rep 2006;8:368-76.

39. Gillis EE, Sullivan JC. Sex differences in hypertension: recent advances. Hypertension 2016;68:1322-7.

40. RN R. Obesity-Related hypertension. Ochsner J 2009;9:133-6.

41. Kotchen TA. Obesity-Related hypertension: epidemiology, pathophysiology, and clinical management. Am J Hypertens 2010;23:1170-8.

42. Al-Goblan AS, Al-Alfi MA, Khan MZ. Mechanism linking diabetes mellitus and obesity. Diabetes Metab Syndr Obes 2014;7:587-91.

43. Kovesdy CP, Furth SL, Zoccali C. Obesity and kidney disease: hidden consequences of the epidemic. Afr J Prim Health Care Fam Med 2017;9:e1-3.

44. Subedi YP, Marais D, Newlands D. Where is Nepal in the nutrition transition? Asia Pac J Clin Nutr 2017;26:358-67. 